\title{
Active Carboxylic Acid-Terminated Alkanethiol Self-Assembled Monolayers on Gold Bead Electrodes for Immobilization of Cytochromes $c$
}

\author{
Ryutaro Tanimura, ${ }^{\text {a,b }}$ Michael G. Hill, ${ }^{\mathrm{c}, *}$ Emanuel Margoliash, ${ }^{\mathrm{d}}$ \\ Katsumi Niki, ${ }^{a, c, * *, z}$ Hiroyuki Ohno, ${ }^{b}$ and Harry B. Gray ${ }^{a}$ \\ ${ }^{a}$ Beckman Institute, California Institute of Technology, Pasadena, California 91125, USA \\ ${ }^{b}$ Department of Biotechnology, Tokyo University of Agriculture and Technology, Koganei, \\ Tokyo, Japan 184-8588 \\ ${ }^{c}$ Department of Chemistry, Occidental College, Los Angeles, California 90041-3314, USA \\ ${ }^{d}$ Department of Biochemistry, Molecular Biology and Cell Biology, Northwestern University, Evanston, \\ Illinois 60208-3500, USA
}

It is extremely difficult to immobilize cytochrome $c$ (cyt $c$ ) on carboxylic acid-terminated alkanethiol self-assembled monolayers (HOOC-SAM) on gold bead electrodes prepared in a hydrogen flame. We found that simple pretreatment of a HOOC-SAM/gold bead electrode by potential cycling in buffer solution in the range $\pm 300 \mathrm{mV}$ prior to immobilization of the protein facilitated stable cyt $c$ binding to HOOC-SAMs. The stability of cyt $c$ on the HOOC-SAMs is independent of the topology of the gold surface. (C) 2002 The Electrochemical Society. [DOI: 10.1149/1.1517770] All rights reserved.

Manuscript submitted June 12, 2002; revised manuscript received August 23, 2002. Available electronically October 7, 2002.

Bowden and co-workers first reported that gold electrodes modified by carboxylic acid-terminated alkanethiol self-assembled monolayers (HOOC-SAM) facilitate direct electron-transfer reactions of cytochromes $c$ (cyt $c$ ) with the electrode. ${ }^{1-3}$ It has long been known that cyt $c$ is immobilized on HOOC-SAMs, and that desorption of cyt $c$ into electrolyte solutions from an HOOC-SAM surface is negligible at low ionic strengths ( $<50 \mathrm{mM}$ phosphate buffer solution) in the $\mathrm{pH}$ range 6-9., Electrostatic interactions between the positively charged lysine-amino groups on cyt $c$ and negatively charged carboxylate termini of the SAMs are analogous to the binding of cyt $c$ to its physiological redox partners. In many previous experiments, flat gold electrodes prepared by vacuum deposition of $\mathrm{Au}$ onto cleaved mica, polished single-crystal silicon, or glass substrates have been used to form HOOC-SAMs on which cyt $c$ was immobilized electrostatically. ${ }^{4-6}$ Bowden and his collaborators stated recently that gold substrate topography markedly influences the degree of interaction between a HOOC-SAM and cyt $c .{ }^{7,8}$ As the topography of the gold substrate becomes smoother, the extent of adsorption and magnitude of electrochemical response of the cyt $c$ immobilized on the HOOC-SAM decreases significantly. The model that was developed predicts that hydrogen bonding between HOOC termini prevails as substrates become smoother. In turn, the electrostatic interaction between HOOC-termini and cyt $c$ becomes weaker and the amount of protein that is immobilized decreases.

Formation of HOOC-SAMs on gold bead electrodes is simple and monolayer coverage is easily attained. However, it was almost impossible to immobilize cyt $c$ on these HOOC-SAMs, as Bowden and collaborators also found. ${ }^{7,8}$ In the present work, we describe how to prepare active HOOC-SAMs on gold bead electrodes for electrochemical investigations of minute amounts of cyt $c$ mutants. The results are compared with those obtained for a roughened goldbead surface.

\section{Experimental}

Chemicals.-Horse heart cyt $c$ and yeast iso-1 cyt $c$ (C102S), in which cysteine-102 was replaced by serine to prevent dimer formation, were purified chromatographically. 3-Mercaptopropionic and 16-mercaptohexadecanoic acids were obtained from Aldrich Chemi-

\footnotetext{
* Electrochemical Society Active Member

** Electrochemical Society Fellow.

z E-mail: nikik@oxy.edu
}

cal Co., St. Louis, MO. 6-Mercaptohexanoic, 8-mercaptooctanoic, and 11-mercaptoundecanoic acids were gifts of Dojindo Molecular Technologies, Gaithersburg, MD. These thiols were used without further purification. Gold wire $(>99.99 \%)$ was purchased from Alfa Aesar and the gold bead electrodes were prepared by melting the gold wire in a hydrogen flame.

Instruments.-Cyclic voltammetric experiments were performed using a BAS CV-50W electrochemical analyzer (Bioanalytical Systems, Inc.). Electrode potentials were measured against $\mathrm{Ag} / \mathrm{AgCl}$ ( satd $\mathrm{KCl}$ ) and the counter electrode was a platinum wire. The surface areas of the gold bead electrodes were in the range 0.12-0.17 $\mathrm{cm}^{2}$. The supporting electrolyte was $10 \mathrm{mM}$ phosphate buffer solution at $\mathrm{pH}$ 7.0. All experiments were carried out at room temperature.

Preparation of active HOOC-SAM modified gold bead electrodes.-The gold bead electrodes were cleaned first in hot concentrated $\mathrm{H}_{2} \mathrm{SO}_{4}$ for about $2 \mathrm{~h}$ after melting the gold wire in a hydrogen flame (this treatment is unnecessary for a fresh gold bead); they were then subjected to an oxidation-reduction cycle (ORC) in $1 \mathrm{M} \mathrm{H}_{2} \mathrm{SO}_{4}$ between -0.3 and $1.5 \mathrm{~V}$ for about 20 cycles at a scan rate of $20 \mathrm{mV} / \mathrm{s}$ until a well-defined voltammogram was obtained. A typical ORC voltammogram of the gold bead electrode in $1 \mathrm{M}$ $\mathrm{H}_{2} \mathrm{SO}_{4}$ is shown in Fig. 1; it was reproducible for most bead electrodes, that is, the structure of the gold bead electrode surface is well controlled in the present work. Any electrodes exhibiting voltammograms unlike that in Fig. 1 were excluded. The gold bead electrodes were thoroughly washed with Milli-Q water, and then sonicated in Milli-Q water for $2 \mathrm{~min}$. The electrodes were soaked for $2 \mathrm{~h}$ in an ethanol solution containing $100 \mu \mathrm{M}$ thiol to form the HOOC-SAMs. Prior to cyt $c$ immobilization on the HOOC-SAMs, the HOOC-SAM coated electrodes were subjected to the ORC treatment between -0.3 and $+0.3 \mathrm{~V}$ until a reproducible cyclic voltammogram $(\mathrm{CV})$ was obtained (nearly flat CVs were obtained without any peaks), and then, these electrodes were soaked in $100 \mu \mathrm{M}$ protein solution (10 mM tris- $\mathrm{HCl}$ buffer at $\mathrm{pH} \mathrm{8.0)} \mathrm{for} 2 \mathrm{~h}$ at room temperature, or overnight at $4^{\circ} \mathrm{C}$. The $\mathrm{CV}$ experiments were carried out in $10 \mathrm{mM}$ phosphate buffer solution at $\mathrm{pH} 7.0$ at room temperature. The amount of HOOC-SAM on the gold bead electrodes was determined by cathodic stripping voltammetry in $0.5 \mathrm{M} \mathrm{KOH}$ at a scan rate of $50 \mathrm{mV} / \mathrm{s}$.

The voltammetric response of cyt $c$ on a pretreated HOOC-SAM on the gold bead electrode was compared with that at HOOC-SAM formed on a chemically etched gold bead electrode by aqua regia diluted threefold with water for $2 \mathrm{~min}$ at room temperature. 


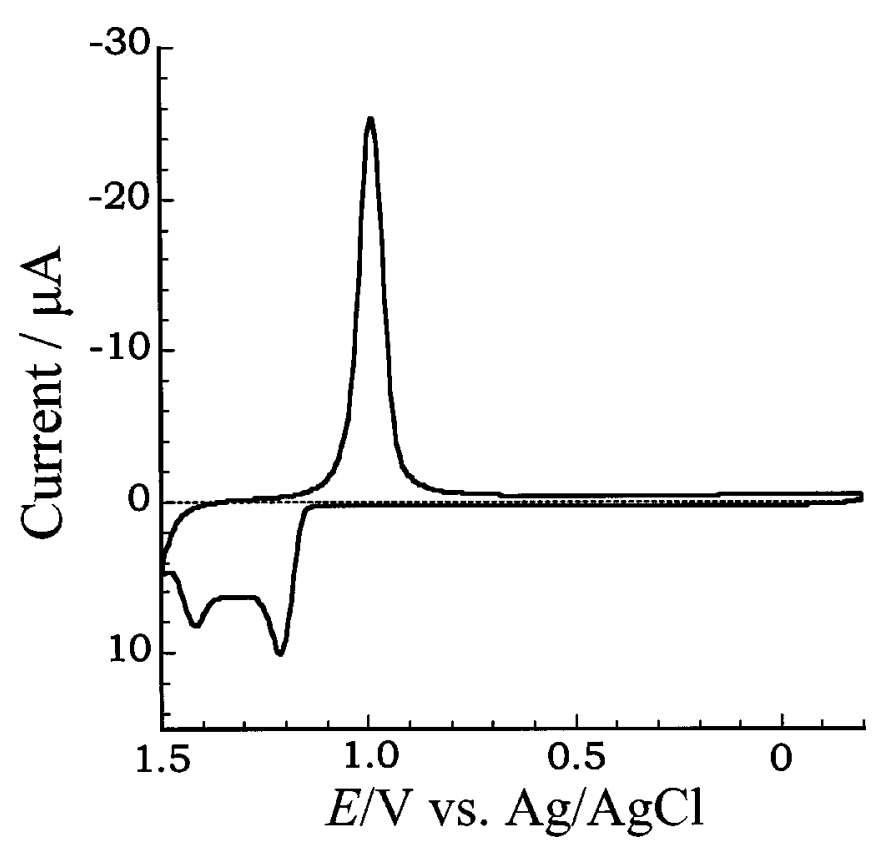

Figure 1. Oxidation-reduction cyclic voltammogram of a gold bead electrode in $1 \mathrm{M} \mathrm{H}_{2} \mathrm{SO}_{4}$.

\section{Results and Discussion}

Carboxylic acid-terminated alkanethiol SAMs on gold bead electrodes.-Cathodic stripping of HOOC-SAMs from gold bead electrodes.-A typical cathodic stripping voltammogram of a $\mathrm{HOOC}\left(\mathrm{CH}_{2}\right)_{10} \mathrm{~S}$-SAM on a gold bead electrode (pretreated) in $0.5 \mathrm{M} \mathrm{KOH}$ is shown in Fig. 2. No significant differences were observed in the cathodic stripping voltammograms between treated and nontreated HOOC-SAM electrodes. These results suggest that the $\pm 300 \mathrm{mV}$ potential cycling does not change the nature of bonding between sulfur atoms and the gold electrode. This stripping voltammogram is similar to that of butanethiolate SAM on evaporated gold (111) film, but the peak potentials were shifted about $130 \mathrm{mV}$ toward more negative potentials. ${ }^{9}$ The variations of two stripping

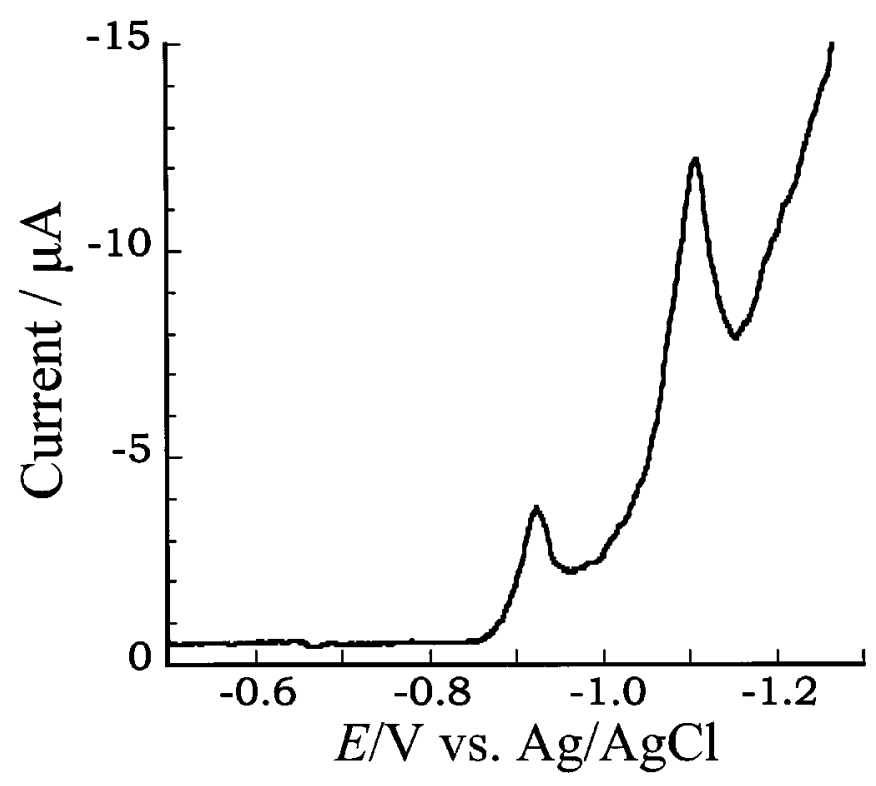

Figure 2. Cathodic stripping voltammogram of a $\mathrm{HOOC}\left(\mathrm{CH}_{2}\right)_{10} \mathrm{SH}$ selfassembled monolayer from a gold bead electrode in $0.5 \mathrm{M} \mathrm{KOH}$ at $50 \mathrm{mV} / \mathrm{s}$.

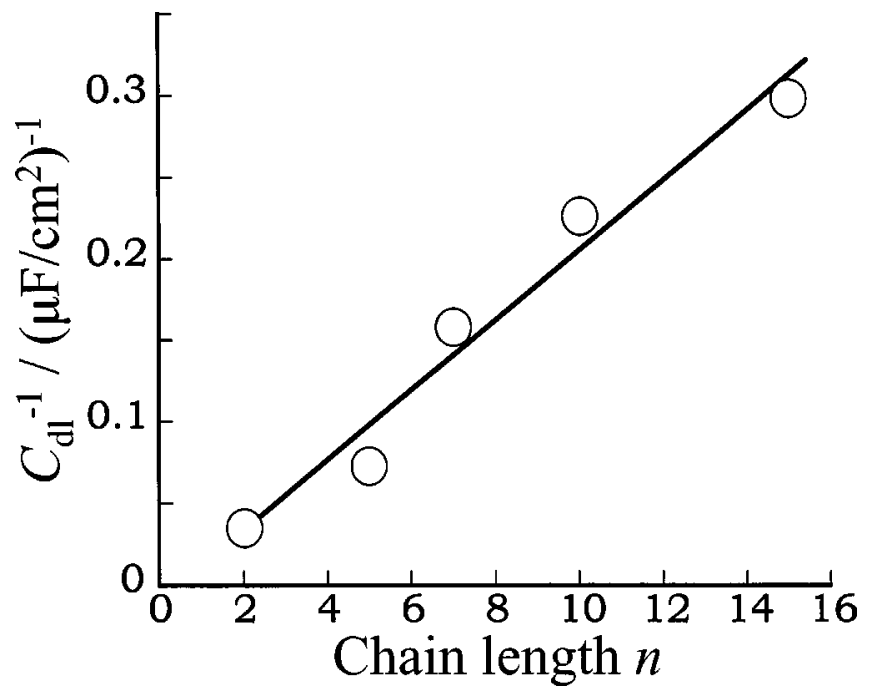

Figure 3. Reciprocal capacitance $v s$. the number of methylene groups, $n$, of a $\mathrm{HOOC}\left(\mathrm{CH}_{2}\right)_{n} \mathrm{SH}$ monolayer-coated gold bead electrode. The capacitances were determined from the charging current between -0.3 and $0.3 \mathrm{~V}$.

peaks are about $\pm 10 \mathrm{mV}$ and the peak separations between the first and second peaks are $0.19 \pm 0.02 \mathrm{~V}$. The full widths at halfmaximum of the first and second peaks of the $\mathrm{HOOC}\left(\mathrm{CH}_{2}\right)_{10} \mathrm{~S}$-SAM are 35 and $45 \mathrm{mV}$, respectively, and these values are greater than $30 \mathrm{mV}$ observed for butanethiol-SAM on an annealed gold (111) film but smaller than $85 \mathrm{mV}$ on a gold (110) single crystal. ${ }^{9}$ The first peak was confirmed to correspond to the reduction of HOOC-SAMs from the annealed gold (111) film. The cathodic desorption potential of the second peak looks like desorption from gold (110) but it may not be that because the gold (110) facet is not observable on a hydrogen-flamed gold bead. ${ }^{10}$ The ratio between the first peak and the second peak is 15:85 regardless of the chain length. That is, the gold (111) surface is estimated to be about $15 \%$ of the total area of the gold beads. The stripping potentials of both the first and second peaks vary linearly with the chain length of the HOOC-SAMs.

Activation of carboxylic acid-terminated alkanethiol SAMs on gold bead electrodes.-It is extremely difficult to immobilize cyt $c$ on HOOC-SAM modified gold bead electrodes that have not been pretreated. Active HOOC-SAM/gold bead electrodes were prepared by potential cycling in $10 \mathrm{mM}$ phosphate buffer solution at $\mathrm{pH} 7.0$ in the range $\pm 300 \mathrm{mV}$ more than 10 times (scan rate: $50 \mathrm{mV} / \mathrm{s}$ ) until a flat CV was obtained. On these active HOOC-SAM surfaces, cyt $c$ can be immobilized readily.

Differential capacitance of HOOC-SAM/gold bead electrodes.-The differential capacitance, $C_{\mathrm{dl}}$, of a HOOC-SAM/gold bead electrode was estimated from the charging current of the $\mathrm{CV}$, which showed that $C_{\mathrm{dl}}$ remained the same from the beginning to the end of many potential cycles. That is, the values of $C_{\mathrm{dl}}$ did not change by surface treatment of the HOOC-SAMs. A plot of $1 / C_{\mathrm{dl}} v s$. the chain length of HOOC-SAM is linear, as shown in Fig. 3, in accord with $C_{\mathrm{dl}}$ values on a roughened gold (evaporated gold film) surface reported by Bowden's group. ${ }^{7}$

Electrode reaction of $\left[\mathrm{Fe}(\mathrm{CN})_{6}\right]^{4-13-}$ on HOOC-SAM/gold bead electrodes.-The $\left[\mathrm{Fe}(\mathrm{CN})_{6}\right]^{4-13-}$ system in $0.2 \mathrm{M} \mathrm{Na}_{2} \mathrm{SO}_{4}$ was used as a redox probe of HOOC-SAM surfaces. Both untreated and pretreated HOOC-SAM coated electrodes were soaked in $5 \mathrm{mM}$ tris-acetate buffer solution at $\mathrm{pH} 7.0$ for about $30 \mathrm{~min}$ to make the difference observable prior to the voltammetric measurements. No difference was observed when the electrodes were soaked in $10 \mathrm{mM}$ phosphate buffer solution at $\mathrm{pH}$ 7.0. The voltammetric response of 


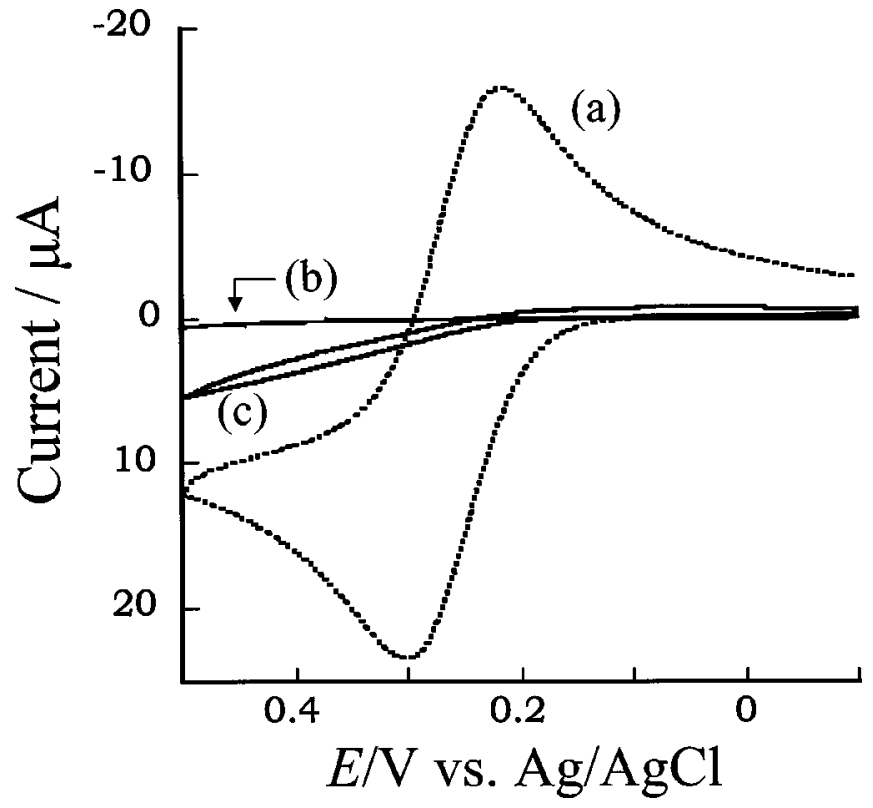

Figure 4. Cyclic voltammogram of $110 \mathrm{mM} \quad \mathrm{K}_{4}\left[\mathrm{Fe}(\mathrm{CN})_{6}\right] \quad$ on a $\mathrm{HOOC}\left(\mathrm{CH}_{2}\right)_{10} \mathrm{~S} /$ gold bead electrode surface in $0.2 \mathrm{M} \mathrm{Na}_{2} \mathrm{SO}_{4}$ at $50 \mathrm{mV} / \mathrm{s}$ : (a) at a bare gold bead; (b) at an untreated $\mathrm{HOOC}\left(\mathrm{CH}_{2}\right)_{10} \mathrm{~S} /$ gold bead electrode; and (c) at a pretreated $\mathrm{HOOC}\left(\mathrm{CH}_{2}\right)_{10} \mathrm{~S} /$ gold bead electrode.

$\left[\mathrm{Fe}(\mathrm{CN})_{6}\right]^{4-13-}$, which was very similar to those reported in previous papers, ${ }^{11,12}$ differed slightly for the untreated and pretreated sur-
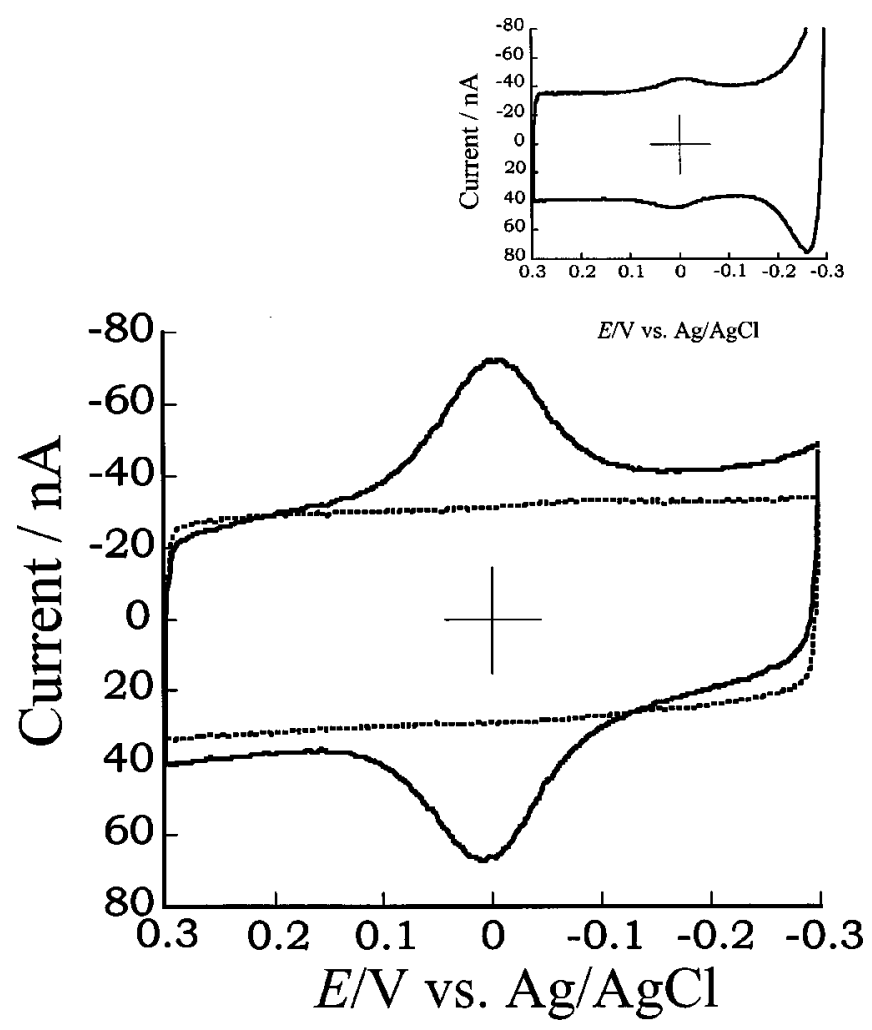

Figure 5. Cyclic voltammogram of horse heart cyt $c$ immobilized on a $\mathrm{HOOC}\left(\mathrm{CH}_{2}\right)_{10} \mathrm{~S} /$ gold bead electrode surface in $10 \mathrm{mM}$ phosphate buffer solution at $\mathrm{pH} 7.0$ with a scan rate $50 \mathrm{mV} / \mathrm{s}$. The dotted line represents the charging current in the supporting electrolyte. Inset: $\mathrm{CV}$ of cyt $c$ on nonpretreated $\mathrm{HOOC}\left(\mathrm{CH}_{2}\right)_{10} \mathrm{~S} /$ gold-bead electrode surface.

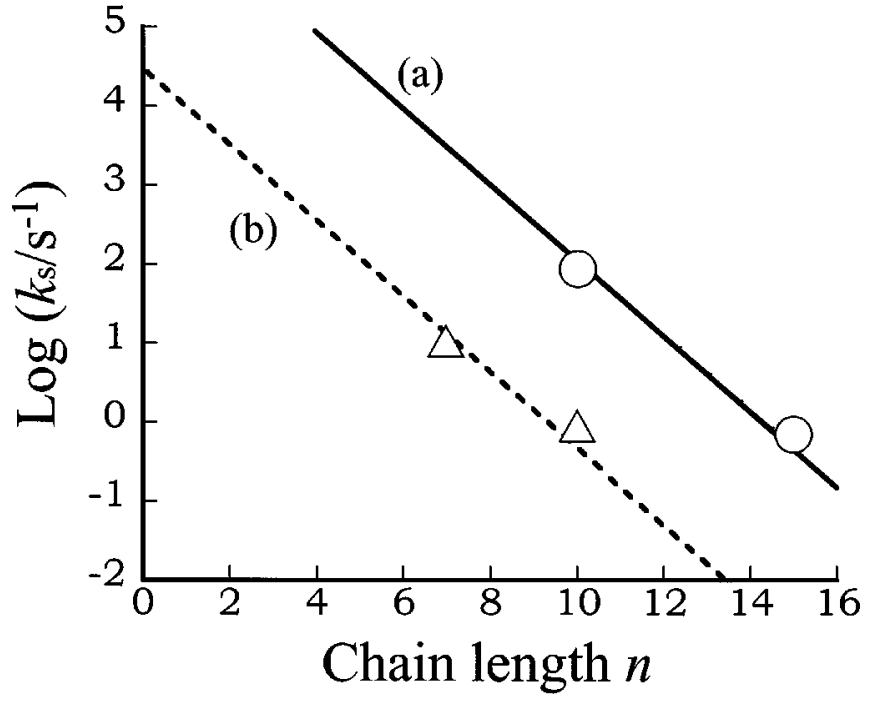

Figure 6. The electron-transfer rate constants of cytochrome $c$ immobilized on a HOOC-SAM/gold bead electrode at the formal potential vs. the number of methylene groups, $n$, of a $\mathrm{HOOC}\left(\mathrm{CH}_{2}\right)_{n} \mathrm{SH}$ monolayer-coated gold bead electrode: (a) horse heart cyt $c$ and (b) yeast iso-1 cyt $c$.

faces. The untreated $\mathrm{HOOC}\left(\mathrm{CH}_{2}\right)_{10} \mathrm{~S}-\mathrm{SAM}$ suppresses the anodic side of the voltammetric response of $\left[\mathrm{Fe}(\mathrm{CN})_{6}\right]^{4-/ 3-}$ more than the treated surface, as shown in Fig. 4. The pretreated SAM may be more hydrophilic than the untreated one.

Cyclic voltammetry of cytochromes c. - It is well established that the topology of a gold electrode surface affects the stability of cyt $c$ adsorbed on HOOC-SAMs. ${ }^{7,8}$ Cytochrome $c$ can be immobilized on etched gold bead electrodes, but the electrode kinetics (voltammograms) of cyt $c$ are not reproducible. After pretreatment of HOOCSAM coated etched gold bead electrodes by potential cycling in the range +300 to $-300 \mathrm{mV}$ prior to protein immobilization, welldefined reproducible results were obtained that agreed with data obtained with pretreated unetched gold bead electrodes. Thus, the activity of the HOOC-SAM surfaces after pretreatment is independent of the gold-substrate surface topology. Figure 5 shows a typical $\mathrm{CV}$ of horse heart cyt $c$ on a $\mathrm{HOOC}\left(\mathrm{CH}_{2}\right)_{10} \mathrm{~S} / \mathrm{Au}$ electrode (both pretreated and nontreated).

Electron-transfer kinetics between cytochromes $c$ and gold electrodes.-Electron-transfer kinetics of horse heart cyt $c$ (wild type) and yeast iso- 1 cyt $c(\mathrm{C} 102 \mathrm{~S})$ mediated by HOOC-SAMs with differing number of methylene groups were determined by cyclic voltammetry. The results shown in Fig. 6 agree well with previous data obtained for cyt $c$ on HOOC-SAM/gold evaporated film electrodes. ${ }^{3,4,13}$

\section{Conclusion}

Active HOOC-SAM/gold bead electrodes have been prepared and tested successfully. Cytochrome $c$ can be easily immobilized electrostatically on these surfaces, which were pretreated by simple potential cycling in the range $\pm 300 \mathrm{mV}$ in buffer solution. The stability of the protein on these activated HOOC-SAMs is independent of the gold surface topology.

\section{Acknowledgment}

Work at Caltech was supported by NIH, NSF, and the Arnold and Mabel Beckman Foundation. E.M. acknowledges support from the Edward Mallinckrodt, Jr., Foundation. Work at Occidental College was supported by the David and Lucille Packard Foundation's Initiative for Interdisciplinary Research. The authors thank Dojindo Molecular Technology for providing carboxylic acid-terminated alkanethiols. 
California Institute of Technology assisted in meeting the publication costs of this article.

\section{References}

1. M. J. Tarlov and E. F. Bowden, J. Am. Chem. Soc., 113, 1847 (1991).

2. M. Collison, E. F. Bowden, and M. J. Tarlov, Langmuir, 8, 1247 (1992).

3. S. Song, R. A. Clark, E. F. Bowden, and M. J. Tarlov, J. Phys. Chem., 97, 6564 (1993).

4. Z. Q. Feng, S. Imabayashi, T. Kakiuchi, and K. Niki, J. Chem. Soc., Faraday Trans., 93, 1367 (1997).

5. A. Avila, B. W. Gregory, K. Niki, and T. M. Cotton, J. Phys. Chem. B, 104, 2759
(2000)

6. K. Niki, Electrochemistry (Tokyo) 70, 82 (2002).

7. M. C. Leopold, J. A. Black, and E. F. Bowden, Langmuir, 18, 978 (2002).

8. M. C. Leopold and E. F. Bowden, Langmuir, 18, 2239 (2002).

9. C.-J. Zhong, J. Zak, and M. D. Porter, J. Electroanal. Chem., 421, 9 (1997)

10. M. Sawaguchi, Electrochemistry (Tokyo) 70, 51 (2002).

11. M. D. Porter, T. B. Bright, D. L. Allara, and C. E. D. Chidsey, J. Am. Chem. Soc., 109, 3559 (1987)

12. K. Takehara, H. Takemura, and Y. Ide, Electrochim. Acta, 39, 817 (1994).

13. A. E. Kasmi, J. M. Wallace, E. F. Bowden, S. M. Binet, and R. J. Linderman, J. Am. Chem. Soc., 120, 225 (1998). 